\title{
Research on PBGS Teaching Model under the Activities Theory
}

\author{
Hechun Wang \\ College of management \\ Shenyang Normal University \\ Shenyang, China \\ hechunwang@126.com \\ Fu Jin \\ College of management \\ Shenyang Normal University \\ Shenyang, China \\ jinfu8655@163.com
}

\author{
Xiaohua Jia \\ College of management \\ Shenyang Normal University \\ Shenyang, China \\ jiaxiaohua926@163.com \\ Yupu Chen \\ College of management \\ Shenyang Normal University \\ Shenyang, China \\ jbbxbb@sina.com
}

\begin{abstract}
With the revolution of new technology, the channel of acquiring new knowledge gains its diversity. Meanwhile, undergraduates have the enough ability to identity, acquire and utilize knowledge. Under the double interaction of the revolution of new technology and the undergraduates' ability of learning, the teaching mode of high level of education in class has to change correspondingly. This paper researches on Teaching Model under the Activities Theory, and takes logistics management course as carrier. Therefore, the logistics curriculum introduces the PBGS teaching mode in teaching, which unifies all kinds of teaching tools, theories and practical problems together, and may clearly expresses the knowledge connotation and react space and place profoundly, and then clear its application scope, enhances student ability to solve practical management problems. The survey shows that application of PBGS teaching model can stimulate students' interest in learning, and improve their comprehensive ability to solve practical problems.
\end{abstract}

Keywords-Activities Theory; PBGS; curriculum; teaching mode

\section{INTRODUCTION}

Currently, college the main goal of teaching reform is to change the traditional mode in which teachers play the main role in class, and to establish a new teaching mode, in which not only teachers can exert their leading roles, but also students can play the main cognitive roles. Therefore, to cultivate undergraduates' ability of innovation and application is an important task of the reformation of teaching mode in modern education. Universities need to build a new teaching mode in order to promote college students' scientific literacy and enhance comprehensive ability[1-2]. Moreover, at present social demand for college graduates is undergoing new changes and employers put more emphasis on their abilities. The changes on social demand stimulate changes on training modes and training objectives inevitably, which require universities to continuously carry through the principle of upgrading students' comprehensive abilities and skills. Therefore, this paper takes the course, "Logistics Management", as a carrier to implement research on teaching mode under the framework of Activities Theory. The reason that paper chooses "logistics management" course as the carrier is the course of "Logistics Management" is complied with the trend of development of producer services in 21 st century and social demand for comprehensive talents.. Nowadays, the course of Logistics Management gains extensive attention, and many universities establish logistics major, and take it as a compulsory course for college students. Especially, the development of logistics simulation software transfer undergraduates' learning of logistics from book logistics to computer logistics. As a result, it has important practical significance by its statistical training application simulation method, which arouses their learning enthusiasm and improves the comprehensive capacity to solve practical problems in society and economy for non-computer professional students.

\section{Current Teaching Situation Analysis}

Although course teaching of logistics management has great significance to improve undergraduates' ability of practice, the pure teaching of logistics stimulation software cannot actually improve undergraduates' ability to find, analyze and solve problems. Existing problems are as follows:

Firstly, there is lack of the organic combination of logistics simulation software and practical management, and lack of ability to find problems for undergraduates. In the process of actual teaching, there is lack of training in students' ability of practice for various reasons. Even if there is certain training, it's just about software basic operation, and it is rare to combine logistics simulation software with actual management in the process of actual teaching. Although there are many popular international logistics simulation software packages such as flexsim, Anylogics, for various reasons, their frequency of utilization is pretty low and they are disconnected with practical management problems. Eventually students after graduate will have no ability to utilize correctly logistics 
simulation software in practical work, and then it makes easy and simple works complicated, which cannot help students to improve their ability of work.

Secondly, there is lack of the combination of logistics simulation analysis software and teaching cases, which make students lack of ability to analyze problems. Nowadays, there is lees domestic books that introduce logistics simulation software, and most of them merely introduce how to operate these software, resulting in that students can't solve the practical problems after learning course of logistics management and logistics simulation software.

Case teaching is not only a process to transfer information knowledge to students but also a process to make student think practical problems. Students can actively analyze comprehensive case with logistics analysis method, and draw conclusions. In case teaching, the biggest problem is about calculations and processing of data in cases. The processing of data cannot be done with logistics simulation software instead of by hand. Meanwhile, statistical results sometimes need to be presented with statistical tables and figures, which also need to use these logistics simulation software.

Thirdly, there is lack of the combination of logistics simulation analysis software and teaching cases, which make students lack of ability to solve problems. This logistics management course requires some basic courses of higher mathematics, mathematical statistics, and so on. Compared with other courses, the contents of every chapters of logistics management have obvious characteristics of independence, but also has close inner link. In the actual teaching practice, in addition to theoretical explanations, it is mainly teaching the application of logistics simulation software, but mainly at operating level, rather than starting from the students' professional background of statistical theory methods, and application conditions, and so on. As lack of mathematical statistics, probability theory, such as foundation, most of students cannot correctly understand the meaning of the results of simulation analysis.

In addition, there still exist some problems in curriculum content standardization and teaching methods. For example, on the teaching content, there is no unified standard teaching materials on logistics simulation software. Most focus on the pure logistics simulation software operation, and the content from the perspective of complex phenomenon in-depth study is far from enough; about teaching method, lectures are mainly taught by teachers, and simultaneously students accept knowledge passively in which there is lack of interaction and communication between teachers and students; for the way of investigation on the results of study, it mainly relies on operating skill examination to check whether students acquire the operational methods of logistics simulation software, and whether know how the methods of cases analysis and actual applied operations and so on. To improve the teaching quality of using logistics simulation software, and to cultivate students practical application ability for statistical analysis, on the basis of traditional teaching, the PBGS (Project -based Group Study) teaching pattern research is committed to make students understand basic knowledge and related basic concepts, understand the basic theory and course law through the introduction of disciplined research results and case study, and make contribute to offer new techniques and new perspectives for management activities through this teaching pattern to combine theories with practice for students, with the purpose of improving students comprehensive ability.

\section{IMPLEMENTATION PLAN OF PBGS TEACHING PATTERN OF MANAGEMENT TRAINING COURSE}

\section{A. Mechanism of PBG Teaching Mode}

At present, the teaching mode of undergraduate follows the mode of "present - accept". In this teaching mode, teachers are aimed to present knowledge and at the same time students receive passively. As a result, students will pay more attention to acquire knowledge instead of cultivating the ability of solving problems[3-5]. This is clearly different with the requirement of the university's ability to train as the core of the university students' quality education, which means the teaching mode, is in urgent need of change.

PBGS teaching pattern of logistics management, to a certain extent, breaks the mode of "present - accept" and it pursues to using subject, harmonious and democratic teaching method, to promote the all-round development of students' cognition, emotion, and skills. Under the driver of problem orientation, practical statistics software courses help undergraduates to improve their ability of discovering, analyzing and solving problems. Meanwhile, in order to make students achieve fusion between theories and tools, it combine with the interpretation of statistics courses After a student proposes a problem, it gets into next cycle, and through continuously discovering new problems existed in management, analyzing and solving them, it reforms a spiral that improves abilities. All kinds of students' cognitive and non-cognitive factors are fully put into it, and students' initiative, individual potential and comprehensive quality are blended into the whole process of PBGS teaching mode, and all aspects of quality get harmoniously developed.

.Therefore, this model has incomparable advantages with traditional mode of "present - accept". Especially in PBGS teaching mode, it reflects the students' subject position[6-7]. Students, therefore, remain the state of active participation, mutual exchanges cooperation, the organization of communication, language expression, literature retrieval in the learning process, and show strong initiative spirit; PBGS contains the cognitive structure in old and new knowledge interaction, constantly update perfect process. The process of PBGS contains cognitive structure in the interaction of old and new knowledge, which is a constantly developed process. Thus, through the PBGS teaching mode, students can make natural connections between various learned knowledge and skills, and uniform a special integrated learning system, and get their potential ability fully exploited. The PBGS teaching mode adapt to the students' psychological characteristics and effectively motivate them to all kinds of cognitive factors in the cognitive process, such as initiative, enthusiasm, independence, creativity, sticking to the truth and exploring spirit and the style of combining theory with practice, and finally get a comprehensive training and development. The internal mechanism is as shown in fig. 1 
recognize individual potential, develop comprehensive quality

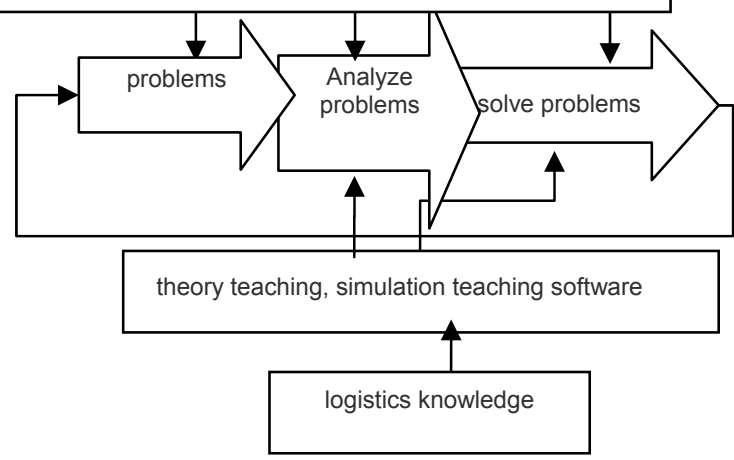

Fig. 1. PBGS mechanism of teaching mode

\section{B. Implementation Content of PBGS Teaching Mode}

This paper takes the teaching activity of logistics management course as a center, and case analysis and empirical research as the main methods, which are based on the PBGS teaching mode, to explore the characteristics of PBGS teaching mode and carry out relative research. The concrete steps of implementation are as follows:

First, the PBGS teaching empirical questionnaire is compiled. Based on empirical research methods, and the combination of logistics simulation software and practical management problems, students find actual management problems by empirical methods, and use library and network information retrieval to search, find and refine theory problems. In the process of problem discovery, students, students cultivate their ability of statistical thinking, strengthen the ability of practice, exercise the ability of expression, and improve the spirit of teamwork through discussion between groups, in which the key is to cultivate students' interest and ability of discovering problems.

Second, the PBGS teaching cases system is compiled. Case teaching is a kind of heuristic education, which uses the typical cases to guide students learning, cultivates the students' ability of innovation. Using case teaching, realizes the organic combination of logistics simulation software and teaching case, improves students' ability to analyze and solve problems. Collecting cases matches the classroom teaching contents and the actual economy and management issues. According to case teaching and new requirements, teacher adjusts case contents, which helps students not only operate logistics simulation software such as Anylogics, but also introduce a higher level of learning, making students applied logistics theories and methods to solve practical problems.

\section{Implementation Targets of PBL Teaching Mode}

Beginning with the double perspective of social demand changes and discipline background, this paper, based on the research on the PBGS teaching mode, tries to study the following aspects of objectives through these teaching works:

Firstly, it is to realize the close combination of theory knowledge, actual management problems and actual practice, and to help students have better understanding in related knowledge, and improve their comprehensive ability of discovering, analyzing and solving problems. Using the PBGS teaching mode. In the process of teaching, teachers combine related knowledge and actual cases to give students lectures, which put theory and practice together, and help students to absorb knowledge, and simultaneously improve their ability of comprehensive application.

Secondly, it is to promote the reformation of undergraduate teaching mode. This paper introduces some teaching tools such as case studies and empirical research with the purpose of switching the center of teaching activity from teachers to students. In this process, it fully mobilizes students' enthusiasm, initiative and creativity, so that students not only fully understand the theoretical knowledge of the practical statistical analysis software and methods, but also can greatly improve the integrated skills of using knowledge. It is of great significance to strengthen the connotation construction of undergraduate teaching and promote the reform of undergraduate teaching mode.

\section{Process Design of PBGS Teaching Implementation}

On the basis of teaching logistics management knowledge and practice of logistics simulation software, it adds case studies into the teaching process of PBGS, and students acquire related cases and design the steps of problem-solving starting with the discovering actual problems, and then read and sort relative searched materials. The specific process of implementation is as follows:

First, students are grouped with the number of class and required to find PBGS cases according to the direction of professional. Students are divided into four major groups according to the original class as teaching units of PBGS. In order to facilitate communication and discussion, each teaching unit is subdivided into 2-3 groups, with 5 to 8 members including one leader in each group. Each group follows the content of teaching and researches cases and papers at least one paper, which are written with misused methods, designed with defection, or further analysis needed.

Secondly, the existing domestic and foreign theoretical literature is combed and refined.. Through reading a wide range of literature, students have a comprehensive and clear understanding of the relevant theories, and basically reform the framework of theoretical research, and then design questionnaire or conduct simulation experiment.

Thirdly, on the basis of literature review, students conduct expert interviews, and carry out on-the-spot interviews for certain enterprises, and then refine research topics through interviews and questionnaire survey. Meanwhile, students further probe and master in the field of practical from the influence of related factors Or each group of students carry out simulation experiment according to the procedure of the logistics simulation experiment.

Fourthly, according to the result of literature review and actual survey, students define the relevant variables, and develop the corresponding scale. Students carry on preliminary survey, test the reliability and validity of scale, generate formal scale after revising, and finally have a large scale and 
questionnaire survey. Meanwhile, each group of students is strict with rule of the empirical analysis of the theory and steps. Each group improves logistics simulation parameters, and improves the simulation efficiency in accordance with simulation experiment requirements.

Fifthly, students discuss the results of analysis. At first, students discuss cases within groups about whether case studies are designed reasonably, index selection is proper, simulation or statistical methods are correct, and analysis explanation results is reasonable or not, and so on. Second, students select out groups' typical cases, and submit to large groups for further discussion. Finally, the result of group discussion is submitted to class discussion conference, and teachers make conclusion on the result of case discussion.

\section{Results of TEACHING RESEARCH}

It is significant to study Logistics Management courses especially in combination with logistics simulation teaching for training the scientific research ability of students of all levels and all kinds of management. As simulation courses have many traits, such as theoretical abstraction, more formulas, each statistical method has specific conditions used, and math courses are not its strengths. Therefore, a student majoring in management has a backlash, and feels difficult to learn. Simultaneously, some students think that it isn't important for their graduation and work in the future comparing with other compulsory courses, and they will lack of interest in learning.

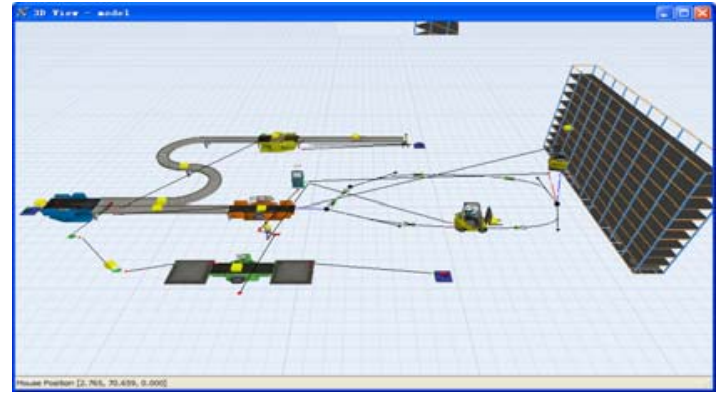

Fig. 2. The logistics simulation result $\mathrm{A}$

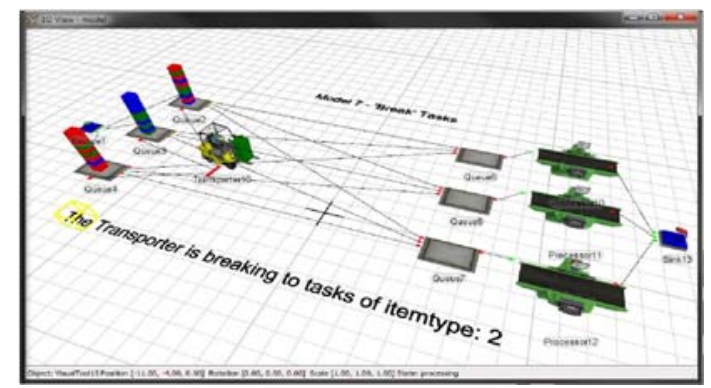

Fig. 3. The logistics simulation result B

It adds the PBGS teaching mode in teaching practice, and improves the previous method of teaching. This paper chooses the class of 2013 students who are majoring in marketing as a research sample, and get feedback after survey. Most of students hold a positive attitude for applying PBGS teaching in the curriculum teaching of logistics management, and after analysis, there is a good effect of this teaching mode. This teaching mode helps students improve their interest in learning, cultivate their ability of asking, finding and solving problems and improve their comprehensive ability of dealing with actual problems.

\section{CONCLUSION}

With the further reform of education system in our country, it become a hot topic in current teaching practice, which is about how to help students to combine basic theory and specific management practice, and to improve their ability to analyze and solve problems. Therefore, it is necessary to enrich the contents and methods of teaching. Moreover, the teaching mode of logistics management based on PBGS teaching mode integrates into logistics, simulation, statistics theory and empirical approaches to the study of the management, and so on. The teaching case and the empirical research questionnaire which is formed by the library, not only can satisfy the demand of the teaching activities on the basic case, and could use some larger scale and rich in content of case and the empirical research activities to mobilize students' participation. By referencing some examples selected from the actual case or journal, targeted questions, organize students to discuss, analysis and summary, help students understand statistical thoughts and statistical methods in specific situation, so as to master the statistical design principles and the basic procedures and on this basis to realize statistical software and achieve mastery through a comprehensive study of statistical theory. It is important to improve students' theoretical level and practical skills, and to improve students' ability to apply their knowledge to practical problems.

\section{ACKNOWLEDGMENT}

National Social Science Fun(14BGL18 2);National Natural Science Foundation of China(71372082,71271141); The seventh education teaching reform project of Shenyang normal university(JG2015-ZD011); 2013 Liaoning Province Social Science Association (L13BRK002); Innovation Team Project of Liaoning Province Education Department (WT2013008).

\section{REFERENCES}

[1] Gang Mao, Gingtang Liu, and Linjing Wu, "Collaborative learning group analysis model based on activity theory and application," Journal of modern distance education research, 2016 (3), pp. 93-103.

[2] Haimin Sun, and Pengfei Liu, "To look at the learning activity by activity theory," China audio-visual education, 2015 (8), pp.29-35.

[3] Wenhao Yu, "Activity theory perspective of the characteristics of the learning team professional ability development,". Journal of modern distance education research, 2015 (2),pp. 87-95.

[4] Haiming $\mathrm{Hu}$, and Zhiting Zhu, "The concept of personal learning environment framework: theoretical orientation activity" Open education research, 2014 (4),pp.84-91

[5] Liang Yu,and Ronghuai Huang, "Activity theory Angle of view of the basic elements of cooperative learning activities under," Journal of distance education, 2014 (1), pp.48-55.

[6] Yufeng Fan, and Xin Li, "Activity theory under the perspective of the virtual learning community building research," China audio-visual education, 2013 (2), pp.43-47

[7] Mei Jiang, "case teaching pattern in the application of medical statistics teaching," China health statistics, 2010 (2),pp.210-211 